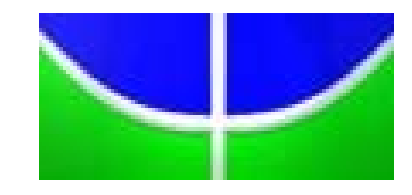

\author{
Universidade de Brasília \\ CET - Centro de Excelência em Turismo
}

Pós-graduação Lato Sensu

Curso de Especialização em Tecnologia de Alimentos

\author{
RAQUEL MARA TEIXEIRA
}

\title{
UMA ABORDAGEM DO CENÁRIO GERAL DE SUCOS INDUSTRIALIZADOS NO CONTEXTO DA ALIMENTAÇÃO SAUDÁVEL
}

\author{
Brasília - DF \\ Fevereiro / 2007
}




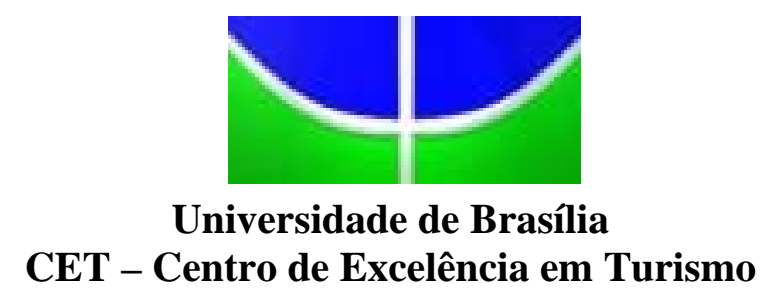

Pós-graduação Lato Sensu

Curso de Especialização em Tecnologia de Alimentos

RAQUEL MARA TEIXEIRA

\title{
UMA ABORDAGEM DO CENÁRIO GERAL DE SUCOS INDUSTRIALIZADOS NO CONTEXTO DA ALIMENTAÇÃO SAUDÁVEL
}

\author{
Monografia apresentada como requisito parcial à \\ obtenção do título de especialista em Tecnologia de \\ Alimentos, Curso de Especialização em Tecnologia \\ de Alimentos, Centro de Excelência em Turismo da \\ Universidade de Brasília. \\ Orientador: Prof ${ }^{\mathrm{a}}$. Drª Wilma M. Coelho Araújo \\ Brasília - DF \\ $\mathrm{Fev} / 2007$
}


Universidade de Brasília

\author{
CET - Centro de Excelência em Turismo
}

RAQUEL MARA TEIXEIRA

\title{
UMA ABORDAGEM DO CENÁRIO GERAL DE SUCOS INDUSTRIALIZADOS NO CONTEXTO DA ALIMENTAÇÃO SAUDÁVEL
}

\begin{abstract}
Monografia apresentada como requisito parcial à obtenção do título de especialista em Tecnologia de Alimentos, Curso de Especialização em Tecnologia de Alimentos, Centro de Excelência em Turismo da Universidade de Brasília.
\end{abstract}

Aprovada em: 07 / 03 /2007

$$
\begin{gathered}
\text { Profa }^{\mathrm{a}} \text { Dr }^{\mathrm{a}} \text {. Wilma M. Coelho Araújo } \\
\text { Orientador: }
\end{gathered}
$$

\author{
Prof $^{\mathrm{a}}$. Msc. Lívia de Lacerda de Oliveira Pineli \\ Examinador 1
}

\author{
Prof. Msc. Antônio José Rezende \\ Examinador 2
}


Teixeira, Raquel Mara

Uma abordagem do cenário geral de sucos industrializados no contexto da alimentação saudável. $48 \mathrm{f}$.

Monografia - Curso de Especialização em Tecnologia de

Alimentos

Brasília - DF, fevereiro de 2007.

Orientador: $\mathrm{Dr}^{\mathrm{a}}$ Wilma Maria Coelho Araújo

1.Sucos industrializados. 2. Legislação 3. Tecnologia

4.Alimentação Saudável 


\section{DEDICATÓRIA}

A Deus, o verdadeiro maestro da minha vida.

A meus amados pais, Sílvio e Zuleide, por me mostrarem que sempre posso ir mais adiante. 


\section{AGRADECIMENTOS}

À querida Professora Wilma, pela confiança, apoio, paciência e carinho, obrigada, de todo coração.

À Professora Raquel Botelho por se mostrar sempre disposta a me ajudar.

Às amigas queridas: Ana Flávia, Silvana, Priscila e Marlise, pelo apoio logístico e emocional a qualquer tempo. 


\section{EPÍGRAFE}

Liberdade é uma palavra que o sonho humano alimenta, não há ninguém que explique e ninguém que não entenda. (Cecília Meireles) 


\section{RESUMO}

O Brasil é um dos três maiores produtores mundiais de frutas e atende a um mercado interno e externo em constante crescimento. $O$ presente trabalho teve como objetivo geral traçar um panorama do mercado de bebidas não-alcoólicas à base de frutas no Brasil e no mundo. A estabilização monetária associada ao ritmo de vida acelerado da sociedade atual $e$ a praticidade de preparo e armazenamento têm levado a um grande aumento do consumo de sucos e refrescos industrializados. Neste contexto, a legislação se faz imprescindível no estabelecimento de regras que contemplem os interesses de todos os envolvidos na cadeia produtiva. Os produtos industrializados, cada vez mais presentes nos hábitos alimentares dos brasileiros, estão altamente relacionados com o aumento dos índices de doenças não transmissíveis, como a obesidade. Neste processo ambíguo sobre a relevância de tais produtos, faz-se importante considerar sua maior garantia de qualidade higiênico-sanitária e seu possível papel promotor de saúde. Conclui-se sobre a importância da função do Estado, por meio das instituições competentes, em promover ações de educação nutricional voltada ao consumidor, a fim de proporcionar aos indivíduos condições de entendimento acerca de suas escolhas alimentares.

\begin{tabular}{|l|l|l|l|}
\hline $\begin{array}{l}\text { 1.Sucos } \\
\text { industrializados }\end{array}$ & 2.Legislação & 3.Tecnologia & 4.Alimentação Saudável \\
\hline
\end{tabular}




\begin{abstract}
Brazil is one of the three world-wide producing greaters of fruits and takes care of a domestic market and external in constant growth. The present work had as objective generality to trace a panorama of the not-alcoholic drink market the base of fruits in Brazil and the world. The monetary stabilization associate to the sped up rhythm of life of the current society and the praticity of preparation and storage has taken to the one great increase of the consumption of juices and industrialized refreshments. In this context, the legislation if makes essential in the establishment of rules that contemplate the interests of all the involved ones in the productive chain. The industrialized products, each time more gifts in the alimentary habits of the Brazilians, highly are related with the increase of the other illnesses chronic degenerative indices, like this obesity. In this ambiguous process on the relevance of such products, important to consider its bigger hygienical-sanitary quality assurance and its possible promotional function of illnesses as the obesity. It is concluded detaching the paper of the State in promoting action of directed nutritional education to the consumer, in order to provide to the individuals conditions of agreement concerning its alimentary choices.
\end{abstract}

\begin{tabular}{|l|l|l|l|}
\hline $\begin{array}{l}\text { 1. Industrialized } \\
\text { juices }\end{array}$ & 2.Legislation & 3. Technology & 3.Healthful Feeding \\
\hline
\end{tabular}




\section{LISTA DE TABELAS}

1. Padrões de Identidade e Qualidade para sucos de frutas, segundo a legislação

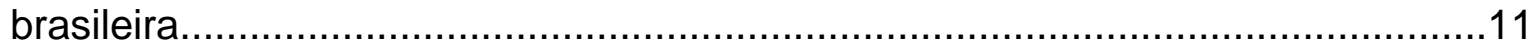

2. Padrões de Identidade e Qualidade para néctares de frutas, segundo a

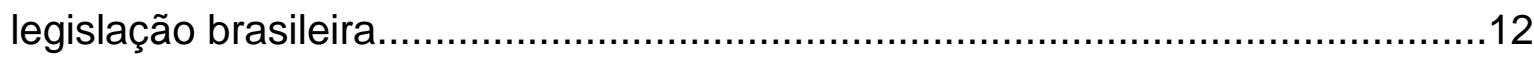




\section{LISTA DE ILUSTRAÇÕES}

Figura 1. Fluxograma da obtenção de suco industrializado de fruta......................14 


\section{SUMÀRIO}

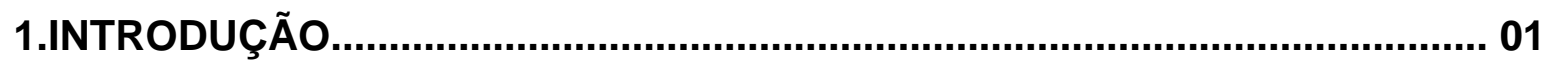

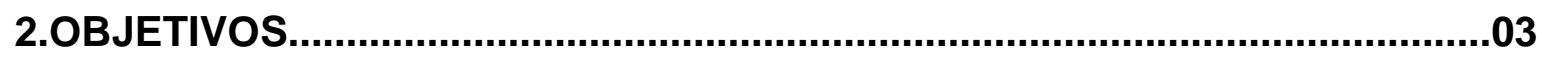

3.METODOLOGIA

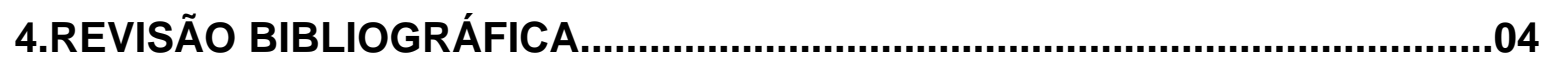

4.1. Cenário do mercado de bebidas não-alcoólicas à base de frutas...................04

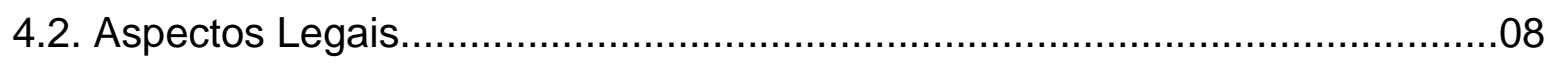

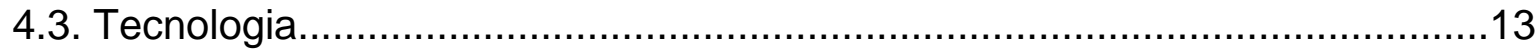

4.4. A Indústria de bebidas no contexto da alimentação saudável........................17

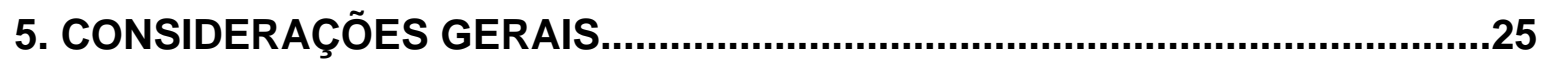

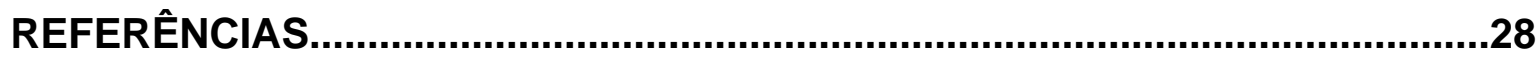




\section{INTRODUÇÃO}

Com aproximadamente 550 milhões de hectares aptos para a agricultura, o Brasil vem procurando incrementar a área já cultivada, de forma a gerar aumento na produção de alimentos para consumo interno e externo (SOUZA, 2001). Com um extenso território e diferentes condições climáticas e tipos de solos, apresenta uma produção agrícola extremamente diversificada. A fruticultura, apesar de representar apenas cerca de $5 \%$ das áreas cultivadas no país, é uma das atividades capazes de assegurar ao Brasil um percentual significativo de volume de produção e da sua pauta de exportação._(SILVA et al, 1999).

Segundo Simarelli (2006), a maturidade da fruticultura nacional está levando o Brasil a ganhar mais espaço no mercado internacional e a conquistar novos clientes na União Européia, maior comprador, além da Ásia, dos Estados Unidos, da própria América Latina e do Oriente Médio.

A evolução da industrialização de frutas no Brasil e no mundo aponta o caminho da agregação de valor. Os alimentos são processados por várias razões: para preservar e estender o prazo de validade, aumentar a digestibilidade, aumentar a biodisponibilidade de alguns nutrientes, melhorar a palatabilidade e a textura, preparar alimentos prontos para consumo, eliminar microorganismos, inativar toxinas, remover partes não comestíveis, inibir fatores antinutricionais e criar novos tipos de alimentos (SHILS, 2002).

Segundo Pereira (2006), a fim de atender a nichos de mercados diferenciados, o segmento das frutas processadas entrou na era da diversificação. As frutas processadas foram incorporadas à rotina das pessoas, em forma de sucos e polpas, conservas, produtos desidratados, água de coco, sorvetes, refrigerantes, confeitos, drinques, néctares, refrescos, barras de cereais, cereais matinais, petiscos, dentre outros. A perspectiva de consumo mundial de alimentos nos países ricos deve se manter constante com poucas exceções, como o consumo de sucos, néctares e drinques à base de frutas.

A produção de sucos prontos para consumo no Brasil começou de maneira incipiente nos anos de 1950, recebendo grande impulso e investimentos no início 
da década seguinte, quando fenômenos climáticos adversos geraram forte demanda por suco de laranja brasileiro nos Estados Unidos. A falta do produto no mercado possibilitou ao Brasil assumir papel de liderança na produção de sucos, com pronunciado destaque para os derivados de laranja de acordo com a Associação Brasileira das Indústrias de Refrigerantes e de Bebidas não alcoólicas (ABIR, 2005).

Dentre outros, o estilo de vida urbano, baseado na praticidade e na falta de tempo e influenciado pela mídia, é um fator que trouxe alterações profundas na forma como as pessoas preparam e se relacionam com os alimentos (MONTEIRO 2005). Em resumo, o país está inserido em um processo de crescimento econômico, evidenciado pelo aumento da renda per capita, urbanização e aumento da participação feminina no mercado de trabalho, o que favorece 0 aumento do consumo de produtos mais elaborados e práticos (CYRILLO et al, 1997).

O consumo de sucos de frutas no Brasil encontra-se em plena expansão em todas as regiões: o Brasil possui mais de 20 pólos de fruticultura distribuídos nas Regiões Norte (Amazônia), Sul (frutas de clima temperado) e Nordeste (culturas irrigadas no Semi-Árido), (PALLET et al, 2005).

$\mathrm{E}$ a indústria, consciente desse potencial brasileiro, está se beneficiando da tecnologia para investir num mercado cada vez mais em expansão. Segundo estimativas do Instituto Brasileiro de Frutas (IBRAF) com dados do Latin Panel/Trends Nielsen/TetraPak, a evolução da produção de sucos, néctares e drinques à base de frutas no Brasil passou de 140 milhões de litros em 2000 para 350 milhões em 2004 (MONTEIRO, 2006).

Este estudo visa apresentar dados recentes sobre o mercado de bebidas não-alcoólicas, enfocando os sucos industrializados prontos para o consumo e seus aspectos de produção, tecnologia, legislação, rotulagem, composição nutricional e sua relação e influência no contexto da alimentação saudável. 


\section{OBJETIVOS}

\subsection{OBJETIVO GERAL}

Descrever o cenário da produção de bebidas não-alcoólicas à base de frutas no contexto da alimentação saudável.

\subsection{OBJETIVOS ESPECÍFICOS}

Definir o conceito de sucos, néctares e bebidas gaseificadas à base de frutas.

Classificar sucos e néctares segundo o Padrão de Identidade e Qualidade da legislação brasileira.

Descrever a tecnologia base de produção de sucos.

Discutir a relação entre a indústria de bebidas e o conceito de alimentação saudável.

\section{METODOLOGIA}

Trata-se de um estudo qualitativo e exploratório. A técnica de pesquisa foi a a documentação indireta com pesquisa bibliográfica e pesquisa documental. $O$ levantamento bibliográfico foi realizado nas bases de dados LILACS, SCIELO e MEDLINE, compreendendo o período de 1996 a 2006, assim como em livros técnicos, específicos da área, nos idiomas português, inglês e espanhol.

As palavras-chaves utilizadas foram: bebidas não-alcoólicas, sucos, bebidas carbonatadas, indústria de bebidas, alimentação saudável,_propaganda e marketing, legislação brasileira.

O corpo do trabalho compreende quatro itens: cenário do mercado de bebidas não-alcoólicas à base de frutas, legislação brasileira acerca do tema, tecnologia de produção e a indústria de bebidas não - alcoólicas no contexto da alimentação saudável. 


\section{Revisão Bibliográfica}

\subsection{Cenário do mercado de bebidas não-alcoólicas à base de frutas}

O crescimento da renda e do poder aquisitivo de uma região ou país modifica os valores individuais e, em termos de alimentação, à medida que aumenta a renda per capita, aumenta o grau de sofisticação na escolha e consumo de alimentos. Os alimentos líquidos assumem importância porque as pessoas deixam de beber apenas água e passam a consumir produtos de maior valor agregado (CIPOLLA). Ainda, um menor tempo disponível para o preparo dos alimentos em casa, devido ao crescimento do número de famílias com duplo rendimento e o trabalho da mulher fora do lar, além da praticidade, rapidez, durabilidade e boa aceitação do produto, criaram uma demanda por alimentos mais convenientemente preparados (AQUINO; PHILIPPI; 2002; SHILS et al, 2002).

$\mathrm{Na}$ esfera global, o setor de bebidas mostra constante ascensão e o consenso entre especialistas é a tendência de um maior aumento do consumo das bebidas não alcoólicas (BERTO, 2003). O mercado de bebidas de tais produtos inclui refrigerantes, sucos, chás, energéticos e engarrafamento de água mineral (BOLETIM NEIT, 2004). Dentre os principais segmentos de bebidas, destaca-se o interesse da sociedade pela comercialização de bebidas à base de frutas, como sucos e polpas de frutas nas suas mais diversas formas de apresentação (FOOD INGREDIENTS, 2003). Segundo Pinheiro (2006), os sucos de frutas são consumidos e apreciados em todo o mundo, não só pelo seu sabor, mas também, por serem fontes naturais de carboidratos, pigmentos, vitaminas, minerais e outros componentes importantes. Berto (2003) complementa que o motivo deste crescimento é a opção do consumidor por alimentos saudáveis e funcionais ${ }^{1} \mathrm{em}$ função do culto à saúde e à boa forma.

\footnotetext{
${ }^{1}$ Alimentos Funcionais - segundo a Agência Nacional de Vigilância Sanitária, são aqueles que produzem efeitos metabólicos ou fisiológicos através da atuação de um nutriente ou não nutriente no crescimento, desenvolvimento, manutenção e em outras funções normais do organismo humano. Desde 1999, são chamados alimentos com alegação de propriedades funcionais.
} 
O mercado mundial de bebidas não alcoólicas cresceu em torno de 3\% nos últimos seis anos. Na Europa Ocidental, o consumo de bebidas à base de vegetais está em ascensão; em 1998 eram 63 milhões de litros; 66 milhões em 1999; 69 milhões em 2000 e 74 milhões em 2001. A Alemanha possui o maior mercado de bebidas não alcoólicas na Europa; seu consumo per capita foi de 253,2 litros em 2000, aproximadamente 16 litros a mais que 1998. Em relação à China, esse mercado é visto como o mercado do futuro; em 1999, seu crescimento foi de $30 \%$ (REINOLD, 2003).

Nos Estados Unidos, pesquisa conduzida por Nielsen e Popkin (2004), analisou a tendência do consumo de bebidas (leite, suco de frutas, refrigerantes, bebidas à base de frutas, café, chá e bebidas alcoólicas) tendo por base o período entre 1977 e 2001. Os autores verificaram que houve um aumento na obtenção de energia proveniente de refrigerantes e bebidas à base de frutas. Em 2003, o crescimento do mercado americano de bebidas não alcoólicas foi de 2,7\% (REINOLD, 2003).

Com um consumo per capita médio de 127litros/ano de bebidas nãoalcoólicas, a América Latina apresentou em 2003 um consumo total de 69 bilhões de litros: Brasil (35\%), México (31\%) e Argentina (12\%) dividem a maior fatia do mercado, 78\%. No mesmo ano, o consumo de bebidas não alcoólicas à base de frutas na América Latina apresentou um montante de 2,6 bilhões de litros, sendo que $73 \%$ deste valor corresponde ao consumo de sucos e néctares. Em relação a este mercado, o Brasil é o segundo grande consumidor de sucos e néctares (29\%) da América Latina, perdendo apenas para o México que representa 36\% deste volume (REINOLD, 2003).

No Brasil, Cipolla relata uma clara mudança de patamar do consumo de alimentos líquidos, refletindo o lançamento de novos produtos e uma possível melhora das condições econômicas da população. Somente quanto à produção de sucos, o Centro de Comércio Internacional da Organização das Nações Unidas (ONU) revela que as vendas de mais de US\$ 1 bilhão em 1999 credenciaram o Brasil como o maior exportador do mundo e responsável por $80 \%$ do total comercializado setorialmente (SOUZA, 2001). Segundo o Wallis-Instituto 
DATAMARK, o consumo brasileiro anual de bebidas não alcoólicas passou de 14,6 bilhões de litros em 1990 para 33,6 bilhões de litros em 2003 (CIPOLLA). No mesmo ano, o consumo de sucos industrializados no Brasil foi de 2,2 bilhões de litros, nas mais diferentes formas (PINHEIRO et al, 2006).

Estima-se que um volume de 6 bilhões de litros de suco sejam produzidos por ano no Brasil. Dentre as diversas categorias desse segmento, o destaque é a de sucos prontos para beber, que cresce $30 \%$ ao ano, segundo estudo da Datamark - Brasil Focus 2002. Dados de 2002 da AC Nielsen revelaram um consumo de sucos prontos para beber de aproximadamente 170 milhões de litros, o que representa um consumo per capita nacional de 1 a 1,5 litros por ano, montante responsável pela geração de uma receita da ordem de 482 milhões de reais neste mesmo ano (LOPEZ, 2004).

Em 2004 dados da mesma instituição comprovam que o mercado de sucos industrializados prontos para consumo cresceu $15,6 \%$ e atingiu proporções maiores do que a de refrigerantes, cujo aumento foi de apenas $6,54 \%$. Este mercado tem movimentado $\mathrm{R} \$ 900$ milhões e 350 milhões de litros, explicando o ingresso e o aumento dos investimentos de empresas nacionais e multinacionais em instalações e desenvolvimento de novos produtos para o setor (MONTEIRO 2006).

Quanto às bebidas gaseificadas, os refrigerantes, dados do Departamento de Agricultura dos Estados Unidos (USDA) mostraram um aumento de 500\% no consumo destas bebidas nos últimos 50 anos (LUDWIG et al, 2001). FRENCH et al. (2003), ao examinarem as tendências do consumo de refrigerantes pelos adolescentes norte-americanos, com idade entre 6 e 17 anos, também constataram uma elevação na média de consumo de $148 \mathrm{~g}$ para $355 \mathrm{~g}$ no período de 1977/1978 e 1994/1998.

No Brasil a década de 1990 representou um grande marco para este setor, com crescimento de 133\% na produção de refrigerantes entre 1992 e 2002, impulsionado basicamente pelo aumento do volume de produção devido a maior oferta de embalagem, principalmente a embalagem à base de polietileno tereftalato (PET), maior eficiência das empresas em distribuir o produto e 
aumentar a oferta e o aumento do poder aquisitivo da população brasileira, haja vista que a má distribuição de renda no país impede uma grande fatia da sociedade de ter acesso ao consumo de refrigerantes (CIPOLLA; QUINTELLA e BOGADO, 2003; NASCIMENTO e YU, 2004).

Amorim (2004) cita que o Plano Real trouxe a estabilização monetária para o país e uma de suas conseqüências foi o aumento do poder aquisitivo das classes médio-baixa e baixa. Com isto, a maior propensão ao consumo de bens até então considerados supérfluos. Com a implantação do Plano Real ocorreu o grande salto em produção e consumo dessas bebidas no Brasil, que registrou um aumento médio superior a 40\%, em comparação a dados obtidos entre 1994 e 1995, segundo a Associação Brasileira das Indústrias de Refrigerantes e de Bebidas Não Alcoólicas (ABIR, 2005).

Apesar do mercado relativamente concentrado, nos últimos anos ocorreu expansão das chamadas "tubaínas", produtos de pequenas marcas regionais e de baixo custo, destinados às classes $C$ que dobraram sua participação no mercado brasileiro no período de 1994-2002. Além do aumento do poder aquisitivo da população, outros fatores favoreceram este movimento, como os preços substancialmente inferiores àqueles praticados pelas principais marcas, estimulando em um primeiro momento a inclusão de segmentos da população de menor poder aquisitivo no mercado de refrigerantes e nos últimos anos, a migração de consumidores de estratos de renda superiores afetados pela estagnação da massa salarial no país (BOLETIM NEIT, 2004).

Apesar das grandes fusões de empresas, como no caso da Companhia de Bebidas das Américas (AmBev), as "tubaínas" ascenderam no mercado de refrigerantes, cujo setor apresenta projeções de crescimento de $5 \%$ ao ano (BOLETIM NEIT, 2004; CIPOLLA). No primeiro semestre de 2004, a participação de mercado das pequenas fábricas foi maior que $30 \%$, superior aos $17 \%$ obtidos pela AmBev, mas permanecendo atrás da líder, Coca-Cola, que detém cerca de $50 \%$ do mercado (ABIR, 2004).

A expansão das marcas regionais tornou a competição mais agressiva, porém, nem sempre saudável e desejável. Dado ser o Brasil um país de grande 
extensão territorial, com oferta ampla e diversificada (aproximadamente 1 milhão de pontos-de-venda), o governo encontra dificuldades em exercer controle rigoroso sobre todos os fabricantes, o que acaba por criar espaços para a concorrência predatória (QUINTELLA e BOGADO, 2003). Maior produtor mundial de refrigerantes, seguido apenas pelos Estados Unidos e pelo México, o Brasil é um mercado com expressivo potencial de crescimento. Apesar de possuir clima propício e estimulador à ingestão de líquidos, o brasileiro consome em média 65 litros de refrigerante ao ano, o que o coloca em discreto $17^{\circ}$ lugar no ranking mundial de consumo per capita (ABIR, 2005; REINOLD, 2003).

Entretanto Ferrari e Soares (2003) consideram seu consumo elevado quando comparado a outras bebidas à base de frutas. Em 1998, o consumo per capita de bebidas carbonatadas ou assemelhados já atingia 71,6 litros. Ainda, segundo Quintella e Bogado (2003), estima-se que cerca de 15 milhões de litros de bebidas não-alcoólicas foram consumidọs pelos brasileiros em 2002, dentre elas, os refrigerantes foram os produtos mais consumidos de norte a sul do Brasil, em um total de 12 bilhões de litros.

Dados do Instituto Brasileiro de Geografia e Estatística (IBGE, 2004) confirmam um fenômeno semelhante em relação ao consumo de tais bebidas, com um aumento que supera $490 \%$. Observou-se que a participação relativa do refrigerante no total de energia da dieta aumentou em 2003 de 0,43\% para 2,12\%, segundo dados do Estudo Nacional de Despesa Familiar (ENDEF), realizado em 1974-1975.

\subsection{Aspectos legais}

Internacionalmente, o Brasil é conhecido como grande produtor de matérias-primas vegetais, por apresentar condições de clima e solo favoráveis ao desenvolvimento da agricultura. Entretanto, a produção primária não é suficiente. Torna-se necessário ao Brasil destacar-se também na produção industrial, agregando valores aos produtos primários, aumentando a produção interna, com excedentes para exportação. Para que haja este incremento na produção de 
bebidas, é necessário estabelecer regras que atendam aos interesses dos produtores, ao poder público (fiscalização) e aos consumidores nacionais e internacionais, para haver a harmonização entre as partes interessadas (VENTURINI, 2005).

Segundo a legislação brasileira, o registro, a padronização, a classificação e ainda, a inspeção e a fiscalização da produção e do comércio de bebidas, em relação aos seus aspectos tecnológicos, competem ao Ministério da Agricultura, Pecuária e Abastecimento (BRASIL, 1994). No âmbito do Ministério da Agricultura, as bebidas que apresentam como principal matéria-prima os vegetais, são fiscalizadas/inspecionadas pelo Serviço de Inspeção Vegetal - SIV (VENTURINI, 2005).

O Art. $10^{\circ}$ do Decreto $\mathrm{n}^{\circ} 2314$, de 1997 , classifica as bebidas em alcoólicas e não-alcoólicas. Conceitua como bebida "todo produto industrializado, destinado à ingestão humana, em estado líquido, sem finalidade medicamentosa ou terapêutica" (BRASIL, 1997). Por outro lado, o Art. 5. da Lei nº 8918 (Brasil, 1994) define que "suco ou sumo é bebida não fermentada, não concentrada e não diluída, obtida da fruta madura e sã, ou parte do vegetal de origem, por processamento tecnológico adequado, submetida a tratamento que assegure a sua apresentação e conservação até o momento do consumo".

O Decreto $n^{\circ} 2314$ define néctares como bebidas não fermentadas, obtidas da diluição em água potável da parte comestível do vegetal e açúcares ou de extrato vegetal e açúcares. Refrigerantes são bebidas gaseificadas, obtidas pela dissolução em água potável, de suco ou extrato vegetal de sua origem, adicionada de açúcares (BRASIL,1997).

A complementação do Decreto é feita por Portarias Interministeriais e Instruções Normativas, sendo que nestas últimas, estão definidos os Padrões de Identidade e Qualidade (PIQ) de alguns sucos e néctares e de refrigerantes.

A Instrução Normativa $N^{0}$ 01, de 7 de janeiro de 2000 aprova 0 Regulamento Técnico Geral para fixação dos Padrões de Identidade e Qualidade dos sucos das seguintes frutas: maracujá, caju, caju alto teor de polpa, caju clarificado, abacaxi, uva, pêra, maçã, limão, lima-ácida e laranja. Os parâmetros 
selecionados para definição do PIQ dos diferentes sucos são: cor, aroma, sabor, sólidos solúveis, acidez total e açúcares totais (Tabela 1).

Quanto aos néctares, a Instrução Normativa No 12, de 04 de setembro de 2003, aprova o Regulamento Técnico para Fixação dos Padrões de Identidade e Qualidade para os néctares de abacaxi, acerola, cajá, caju, goiaba, graviola, mamão, manga, maracujá, pêssego e pitanga. Ainda, complementa no artigo $3^{\circ}$ que o néctar cuja quantidade mínima de polpa de uma determinada fruta não tenha sido fixada em Regulamento Técnico específico deve conter no mínimo 30\% da respectiva polpa, ressalvado o caso de fruta com acidez ou conteúdo de polpa muito elevado ou sabor muito forte e, neste caso, o conteúdo de polpa não deve ser inferior a 20\%. Os parâmetros para definição dos PIQ's para néctares se assemelham aos parâmetros para sucos: cor, aroma, sabor, teor de polpa ou suco, sólidos solúveis, acidez total e açúcares totais (Tabela 2). 
Tabela 1. Padrões de Identidade e Qualidade para sucos de frutas, segundo a legislação brasileira (BRASIL, 2000).

\begin{tabular}{|c|c|c|c|c|c|c|c|c|c|c|c|}
\hline & Maracujá & Caju & $\begin{array}{l}\text { Caju alto teor de } \\
\text { polpa }\end{array}$ & Caju clarificado & Abacaxi & Uva & Pêra & Maçã & Limão & Lima-ácida & Laranja \\
\hline Cor & $\begin{array}{l}\text { De amarela } \\
\text { a } \\
\text { alaranjado }\end{array}$ & $\begin{array}{ll}\text { Variando } & \text { do } \\
\text { branco } & \text { ao } \\
\text { amarelado } & \end{array}$ & $\begin{array}{ll}\text { Variando } & \text { do } \\
\text { branco } & \text { ao } \\
\text { amarelado } & \end{array}$ & $\begin{array}{ll}\text { Variando } & \text { do } \\
\text { incolor } & \text { ao } \\
\text { amarelado } & \\
\text { translúcido } & \end{array}$ & $\begin{array}{l}\text { Variando } \\
\text { do } \\
\text { branco } \\
\text { ao } \\
\text { marfim }\end{array}$ & $\begin{array}{l}\text { Vinho, } \\
\text { rosado ou } \\
\text { translúcido } \\
\text { (branco) }\end{array}$ & $\begin{array}{l}\text { Branco } \\
\text { translúcid } \\
\text { o }\end{array}$ & $\begin{array}{l}\text { Branco a } \\
\text { translúcido. }\end{array}$ & $\begin{array}{l}\text { Translúcido } \\
\text { a } \\
\text { amarelado. }\end{array}$ & $\begin{array}{l}\text { Translúcido } \\
\text { a } \\
\text { amarelado. }\end{array}$ & Amarelo \\
\hline Sabor & $\begin{array}{l}\text { Próprio } \mathrm{e} \\
\text { ácido }\end{array}$ & $\begin{array}{l}\text { Próprio, } \\
\text { levemente } \\
\text { ácido } \quad \text { e } \\
\text { adstringente. }\end{array}$ & $\begin{array}{l}\text { Próprio, } \\
\text { levemente ácido e } \\
\text { adstringente. }\end{array}$ & $\begin{array}{l}\text { Próprio, } \\
\text { levemente ácido } \\
\text { e adstringente }\end{array}$ & Próprio. & Próprio. & Próprio. & Próprio. & Próprio. & Próprio. & Próprio. \\
\hline Aroma & Próprio & Próprio & Próprio & - & Próprio. & Próprio. & Próprio. & Próprio. & Próprio. & Próprio. & Próprio. \\
\hline $\begin{array}{l}\text { Sólidos solúveis } \\
\text { em }{ }^{\circ B} \text { Brix, a } 20^{\circ} \\
\text { C }\end{array}$ & $\begin{array}{l}\text { Mín:11,0 } \\
\text { Máx:- }\end{array}$ & $\begin{array}{l}\text { Mín:10,0 } \\
\text { Máx: - }\end{array}$ & $\begin{array}{l}\text { Mín:10,0 } \\
\text { Máx: - }\end{array}$ & $\begin{array}{l}\text { Mín:10,0 } \\
\text { Máx: - }\end{array}$ & $\begin{array}{l}\text { Mín:11,0 } \\
\text { Máx: - }\end{array}$ & $\begin{array}{l}\text { Mín:14,0 } \\
\text { Máx: - }\end{array}$ & $\begin{array}{l}\text { Mín:8,0 } \\
\text { Máx: - }\end{array}$ & $\begin{array}{l}\text { Mín:10,5 } \\
\text { Máx: - }\end{array}$ & & & $\begin{array}{l}\text { Mín:7,0 } \\
\text { Máx: - }\end{array}$ \\
\hline $\begin{array}{lr}\text { Acidez } & \text { total } \\
\text { expressa } & \text { em } \\
\text { ácidos }(\mathrm{g} / 100 \mathrm{~g})\end{array}$ & $\begin{array}{l}\text { Min: } 2,5 \\
\text { Max: - }\end{array}$ & $\begin{array}{l}\text { Mín:0,3 } \\
\text { Máx:- }\end{array}$ & $\begin{array}{l}\text { Mín:0,3 } \\
\text { Máx:- }\end{array}$ & $\begin{array}{l}\text { Mín:0,25 } \\
\text { Máx:- }\end{array}$ & $\begin{array}{l}\text { Mín:0,3 } \\
\text { Máx:- }\end{array}$ & $\begin{array}{l}\text { Mín:0,41 } \\
\text { Máx: - }\end{array}$ & $\begin{array}{l}\text { Mín:0,15 } \\
\text { Máx: - }\end{array}$ & $\begin{array}{l}\text { Mín:0,15 } \\
\text { Máx: - }\end{array}$ & $\begin{array}{l}\text { Mín:5,0 } \\
\text { Máx: - }\end{array}$ & $\begin{array}{l}\text { Mín:5,0 } \\
\text { Máx: - }\end{array}$ & $\begin{array}{l}\text { Mín:7,0 } \\
\text { Máx: - }\end{array}$ \\
\hline $\begin{array}{l}\text { Açucares totais } \\
\text { naturais } \\
(\mathrm{g} / 100 \mathrm{~g})\end{array}$ & $\begin{array}{l}\text { Min: - } \\
\text { Máx:18,0 }\end{array}$ & $\begin{array}{l}\text { Mín: - } \\
\text { Máx: 15,0 }\end{array}$ & $\begin{array}{l}\text { Mín: - } \\
\text { Máx: 15,0 }\end{array}$ & $\begin{array}{l}\text { Mín: - } \\
\text { Máx: 15,0 }\end{array}$ & $\begin{array}{l}\text { Mín: - } \\
\text { Máx: } \\
15,0\end{array}$ & $\begin{array}{l}\text { Mín: - } \\
\text { Máx: 20,0 }\end{array}$ & $\begin{array}{l}\text { Mín: - } \\
\text { Máx: } \\
12,5\end{array}$ & $\begin{array}{l}\text { Mín: - } \\
\text { Máx: 13,5 }\end{array}$ & & & $\begin{array}{l}\text { Mín: - } \\
\text { Máx: 13,0 }\end{array}$ \\
\hline $\begin{array}{l}\text { Ácido ascórbico } \\
(\mathrm{mg} / 100 \mathrm{~g})\end{array}$ & & $\begin{array}{l}\text { Mín:80,0 } \\
\text { Máx:- }\end{array}$ & $\begin{array}{l}\text { Mín:80,0 } \\
\text { Máx:- }\end{array}$ & $\begin{array}{l}\text { Mín:60,0 } \\
\text { Máx:- }\end{array}$ & & & & & $\begin{array}{l}\text { Mín:20,0 } \\
\text { Máx:- }\end{array}$ & $\begin{array}{l}\text { Mín:20,0 } \\
\text { Máx:- }\end{array}$ & $\begin{array}{l}\text { Mín:25,0 } \\
\text { Máx:- }\end{array}$ \\
\hline $\begin{array}{l}\text { Sólidos } \\
\text { insolúveis \% v/v }\end{array}$ & & & & & & $\begin{array}{l}\text { Mín: - } \\
\text { Máx: 5,0 }\end{array}$ & & & & & \\
\hline $\begin{array}{l}\text { Acides } \quad \text { volátil } \\
(\mathrm{g} / 100 \mathrm{~g})\end{array}$ & & & & & & $\begin{array}{l}\text { Mín: - } \\
\text { Máx: 0,05 }\end{array}$ & & $\begin{array}{l}\text { Mín: - } \\
\text { Máx: 0,04 }\end{array}$ & & & \\
\hline $\begin{array}{l}\text { Óleo essencial } \\
\% v / v\end{array}$ & & & & & & & & & $\begin{array}{l}\text { Mín: - } \\
\text { Máx: 0,025 }\end{array}$ & $\begin{array}{l}\text { Mín: - } \\
\text { Máx: 0,025 }\end{array}$ & $\begin{array}{l}\text { Mín: - } \\
\text { Máx: 0,035 }\end{array}$ \\
\hline
\end{tabular}


Tabela 2. Padrões de Identidade e Qualidade para néctares de frutas, segundo a legislação brasileira (BRASIL, 2003).

\begin{tabular}{|c|c|c|c|c|c|c|c|c|c|c|c|}
\hline & Abacaxi & Acerola & Cajá & Caju & Goiaba & Graviola & Mamão & Manga & Maracujá & Pêssego & Pitanga \\
\hline Cor & $\begin{array}{l}\text { Variando de } \\
\text { branca a } \\
\text { amarela }\end{array}$ & $\begin{array}{lr}\text { Variando } & \text { de } \\
\text { amarelada } & \text { a } \\
\text { vermelha. } & \end{array}$ & $\begin{array}{lr}\text { Variando } & \text { de } \\
\text { amarelada } & \text { a } \\
\text { alaranjada. } & \end{array}$ & Amarela clara. & $\begin{array}{l}\text { Variando } \\
\text { de } \\
\text { branca a } \\
\text { avermelh } \\
\text { ada. }\end{array}$ & $\begin{array}{l}\text { Variando de } \\
\text { branca a } \\
\text { marfim. }\end{array}$ & $\begin{array}{l}\text { Variando } \\
\text { de } \\
\text { amarela } \\
\text { a } \\
\text { avermelh } \\
\text { ada. }\end{array}$ & $\begin{array}{l}\text { Variando } \\
\text { de amarela } \\
\text { a } \\
\text { alaranjada. }\end{array}$ & $\begin{array}{l}\text { Variando de } \\
\text { amarela a } \\
\text { alaranjada. }\end{array}$ & Amarelada. & $\begin{array}{l}\text { Variando } \\
\text { de } \\
\text { alaranjada } \\
\text { a vermelha. }\end{array}$ \\
\hline Sabor & $\begin{array}{l}\text { Característi } \\
\text { co. }\end{array}$ & Característico. & Característico. & Característico. & $\begin{array}{l}\text { Caracterí } \\
\text { stico. }\end{array}$ & $\begin{array}{l}\text { Característi } \\
\text { co. }\end{array}$ & $\begin{array}{l}\text { Caracterí } \\
\text { stico. }\end{array}$ & $\begin{array}{l}\text { Característi } \\
\text { co. }\end{array}$ & $\begin{array}{l}\text { Característi } \\
\text { co. }\end{array}$ & $\begin{array}{l}\text { Característi } \\
\text { co. }\end{array}$ & $\begin{array}{l}\text { Característi } \\
\text { co. }\end{array}$ \\
\hline Aroma & Próprio & Próprio & Próprio & Próprio & Próprio. & Próprio. & Próprio. & Próprio. & Próprio. & Próprio. & Próprio. \\
\hline $\begin{array}{ll}\text { Teor de } & \text { polpa } \\
\text { ou } & \text { suco } \\
(\mathrm{g} / 100 \mathrm{~g}) & \end{array}$ & $\begin{array}{l}\text { Mín:40,0 } \\
\text { Máx:- }\end{array}$ & $\begin{array}{l}\text { Mín:25,0 } \\
\text { Máx:- }\end{array}$ & $\begin{array}{l}\text { Mín:25,0 } \\
\text { Máx:- }\end{array}$ & $\begin{array}{l}\text { Mín:15,0 } \\
\text { Máx:- }\end{array}$ & $\begin{array}{l}\text { Mín:35,0 } \\
\text { Máx:- }\end{array}$ & $\begin{array}{l}\text { Mín:35,0 } \\
\text { Máx:- }\end{array}$ & $\begin{array}{l}\text { Mín:35,0 } \\
\text { Máx:- }\end{array}$ & $\begin{array}{l}\text { Mín:40,0 } \\
\text { Máx:- }\end{array}$ & $\begin{array}{l}\text { Mín:10,0 } \\
\text { Máx:- }\end{array}$ & $\begin{array}{l}\text { Mín:40,0 } \\
\text { Máx:- }\end{array}$ & $\begin{array}{l}\text { Mín:25,0 } \\
\text { Máx:- }\end{array}$ \\
\hline $\begin{array}{l}\text { Sólidos solúveis } \\
\text { em }{ }^{\circ B} \text { Brix, a } 20^{\circ} \\
\text { C }\end{array}$ & $\begin{array}{l}\text { Mín:11,0 } \\
\text { Máx:- }\end{array}$ & $\begin{array}{l}\text { Mín:10,0 } \\
\text { Máx: - }\end{array}$ & $\begin{array}{l}\text { Mín:110 } \\
\text { Máx: - }\end{array}$ & $\begin{array}{l}\text { Mín:10,0 } \\
\text { Máx: - }\end{array}$ & $\begin{array}{l}\text { Mín:10,0 } \\
\text { Máx: - }\end{array}$ & $\begin{array}{l}\text { Mín:10,0 } \\
\text { Máx: - }\end{array}$ & $\begin{array}{l}\text { Mín:10,0 } \\
\text { Máx: - }\end{array}$ & $\begin{array}{l}\text { Mín:10,0 } \\
\text { Máx: - }\end{array}$ & $\begin{array}{l}\text { Mín:11,0 } \\
\text { Máx: - }\end{array}$ & $\begin{array}{l}\text { Mín:11,0 } \\
\text { Máx: - }\end{array}$ & $\begin{array}{l}\text { Mín:10,0 } \\
\text { Máx: - }\end{array}$ \\
\hline $\begin{array}{lr}\text { Acidez } & \text { total } \\
\text { expressa } & \text { em } \\
\text { ácidos }(\mathrm{g} / 100 \mathrm{~g})\end{array}$ & $\begin{array}{l}\text { Min: 0,12 } \\
\text { Max: - }\end{array}$ & $\begin{array}{l}\text { Mín:0,2 } \\
\text { Máx:- }\end{array}$ & $\begin{array}{l}\text { Mín:0,2 } \\
\text { Máx:- }\end{array}$ & $\begin{array}{l}\text { Mín:0,12 } \\
\text { Máx:- }\end{array}$ & $\begin{array}{l}\text { Mín:0,1 } \\
\text { Máx:- }\end{array}$ & $\begin{array}{l}\text { Mín:0,10 } \\
\text { Máx: - }\end{array}$ & $\begin{array}{l}\text { Mín:0,10 } \\
\text { Máx: - }\end{array}$ & $\begin{array}{l}\text { Mín:0,2 } \\
\text { Máx: - }\end{array}$ & $\begin{array}{l}\text { Mín:0,25 } \\
\text { Máx: - }\end{array}$ & $\begin{array}{l}\text { Mín:0,15 } \\
\text { Máx: - }\end{array}$ & $\begin{array}{l}\text { Mín:0,2 } \\
\text { Máx: - }\end{array}$ \\
\hline $\begin{array}{l}\text { Açucares totais } \\
\text { naturais } \\
(\mathrm{g} / 100 \mathrm{~g})\end{array}$ & $\begin{array}{l}\text { Min: 8,0 } \\
\text { Máx: - }\end{array}$ & $\begin{array}{l}\text { Mín: 6,0 } \\
\text { Máx: - }\end{array}$ & $\begin{array}{l}\text { Mín: 7,0 } \\
\text { Máx: }\end{array}$ & $\begin{array}{l}\text { Mín: 7,0 } \\
\text { Máx: - }\end{array}$ & $\begin{array}{l}\text { Mín: 7,0 } \\
\text { Máx: - }\end{array}$ & $\begin{array}{l}\text { Mín: 7,0 } \\
\text { Máx: - }\end{array}$ & $\begin{array}{l}\text { Mín: 6,0 } \\
\text { Máx: - }\end{array}$ & $\begin{array}{l}\text { Mín: 7,0 } \\
\text { Máx: - }\end{array}$ & $\begin{array}{l}\text { Mín: 7,0 } \\
\text { Máx: }\end{array}$ & $\begin{array}{l}\text { Mín: 7,0 } \\
\text { Máx: }\end{array}$ & $\begin{array}{l}\text { Mín: 6,0 } \\
\text { Máx: }\end{array}$ \\
\hline $\begin{array}{l}\text { Ácido ascórbico } \\
(\mathrm{mg} / 100 \mathrm{~g})\end{array}$ & & $\begin{array}{l}\text { Mín:160,0 } \\
\text { Máx:- }\end{array}$ & & $\begin{array}{l}\text { Mín:15,0 } \\
\text { Máx:- }\end{array}$ & $\begin{array}{l}\text { Mín:14,0 } \\
\text { Máx:- }\end{array}$ & $\begin{array}{l}\text { Mín:14,0 } \\
\text { Máx:- }\end{array}$ & & & & & \\
\hline
\end{tabular}




\subsection{Tecnologia}

A Sociedade Brasileira de Ciência e Tecnologia de Alimentos define tecnologia de allimentos como sendo a aplicação de métodos e da técnica para o preparo, armazenamento, processamento, controle, embalagem, distribuição e utilização dos alimentos (GAVA, 1978).

A tecnologia alimentar é o vínculo entre a produção e o consumo dos alimentos e se ocupa de sua adequada manipulação, elaboração, preservação, armazenamento e comercialização. Para que possa alcançar um bom rendimento, deve a tecnologia estar intimamente associada aos métodos e progressos da produção agrícola ${ }_{\perp}$ de um lado, e aos princípios e práticas da nutrição humana, do outro lado (GAVA, 1978).

Os sucos de frutas são obtidos a partir de frutas frescas, maduras e lavadas através de um processo industrial tecnologicamente adequado. Não podem ser diluídos nem conter odor ou sabor estranhos, e/ou algum indício de fermentação. Podem ser estabilizados através de algum tratamento físico ou químico autorizado ou conter algum tipo de aditivo, que garanta a sua conservação e características atrativas ao consumidor (EMBRAPA/SEBRAE, 1997).

$\mathrm{O}$ aspecto é provavelmente $\mathrm{o}$ atributo de qualidade que determina o valor comercial de um produto, pois o consumidor associa determinada qualidade com o aspecto. O sabor das frutas, bem como de seus sucos, é o resultado de uma interação de características de odor, gosto e sensações táteis, determinando o equilíbrio de sensações características de cada produto (WILLS et al, 1984).

O tipo de fruta, bem como suas variedades, maturidade, condições climáticas e práticas de cultura, influenciam a composição do suco, assim como seu processamento (RODRIGUES, 2002).

Para a obtenção do produto (Figura 1), em uma primeira etapa se faz a extração da polpa. Após a obtenção da polpa, o processamento é basicamente realizado através de etapas de inativação enzimática, prensagem, refino ou clarificação, desaeração, pasteurização, formulação, envase e armazenamento (VARNAN e SUTHERLAND, 1994). 


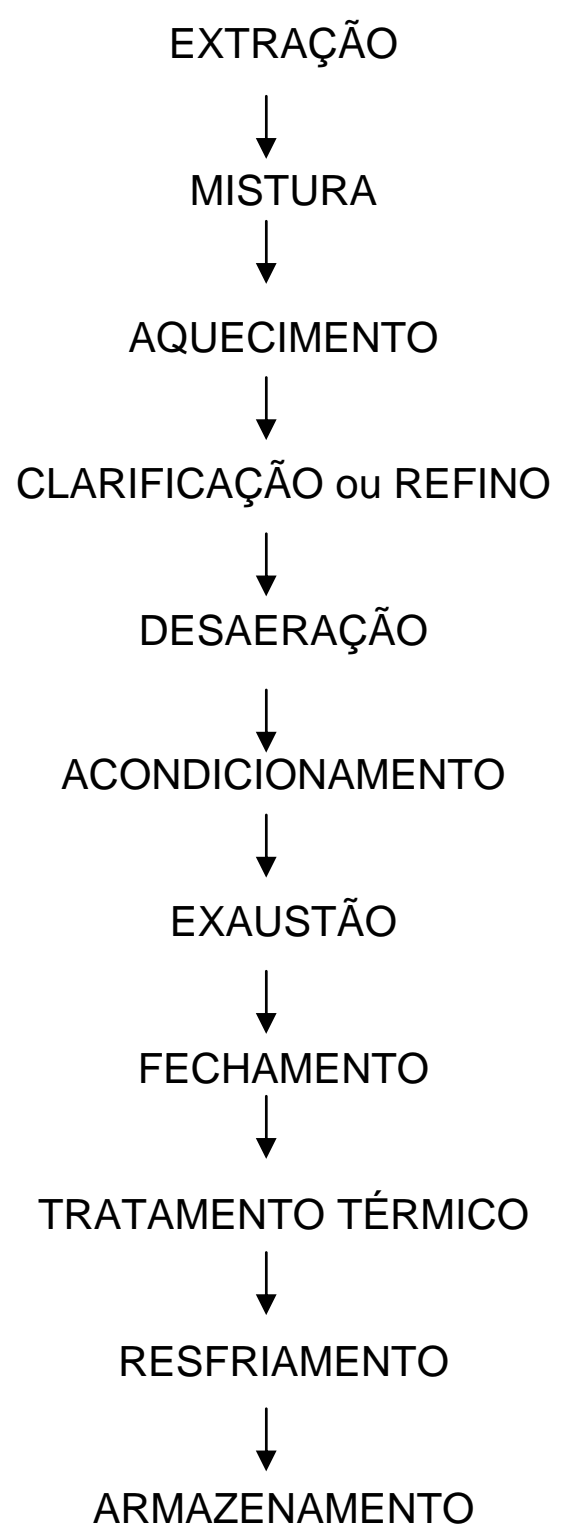

Figura 1 - Fluxograma da obtenção de suco industrializado de fruta.

A inativação pelo calor consiste em submeter o produto, imediatamente após o despolpamento a um tratamento térmico, que depende de cada fruta, com o objetivo de inibir ou minimizar as transformações enzimáticas e reduzir a carga microbiana, ambas indesejáveis e que podem deteriorar o produto. A inativação térmica, dentre outras vantagens, confere ao suco a estabilidade da cor e da 
consistência, parâmetros importantes para a qualidade visual do produto (EMBRAPA/SEBRAE, 1997).

Diversos processos podem ser usados para extração do suco, dentre eles a prensagem. A escolha da prensa depende de vários fatores: forma de operação, capacidade, custos, rendimento de extração e utilização de auxiliares de prensagem (APRIA, 1971). Atualmente outros processos estão sendo utilizados: extração por difusão e liquidificação por enzimas (CLIFF et al, 1991).

A polpa de algumas frutas é composta de grande número de fibras e resíduos sólidos, contendo pectina e celulose, que normalmente devem ser removidos para obter-se um produto mais homogêneo. O acabamento do suco ou operação de refino (finishing) tem por objetivo a remoção da polpa grosseira, que pode diminuir a eficiência do tratamento térmico, prejudicar a qualidade da bebida e o aspecto visual do produto. A intensidade da operação de refino é função do tipo de produto desejado. Para tal, podem ser utilizados filtros ou despolpadeiras com peneiras de pequena abertura (VENTURINI, 2005).

Dependendo do tipo de produto final desejado, o suco requer uma etapa de clarificação. De acordo com as características físico-químicas de cada fruta, seus sucos apresentam diferentes graus de turvação natural. A turbidez e sedimentos dos sucos são devidos à presença de materiais insolúveis como fragmentos celulares provenientes diretamente do tecido polposo, pectinas, amidos ou componentes não perfeitamente dissolvidos (LEA, 1995; BORGES, 1998, SANTIN, 2004). VAILLANT et al. (2001) estudaram a clarificação, que visa a transparência e homogeneidade dos sucos e polpa de frutas. A preparação para a clarificação do suco começa com o tratamento da polpa com enzimas pectinolíticas. O uso de enzimas reduz a viscosidade do suco, facilitando a operação de filtração. Além disso, a baixa viscosidade favorece a troca de calor durante os tratamentos térmicos. Geralmente, quando o nome comercial não indica o tipo de enzima usada trata-se de composto com várias enzimas, pectinolíticas, amilolíticas e hemicelulósica (SAINZ et al, 2001).

O oxigênio incorporado ao suco nas etapas de extração e refino causa oxidação, destruindo algumas vitaminas e prejudicando a cor e o sabor do suco. O 
desaerador é, em geral, colocado em linha com o pasteurizador, para que o suco só atinja a temperatura de pasteurização após a eliminação do oxigênio (VENTURINI, 2005). Cada suco de fruta apresenta características diferentes e a relação tempo e temperatura do tratamento térmico difere de fruta para fruta e será função do processo a que foi submetida a polpa anteriormente (EMBRAPA/SEBRAE, 1997).

O tratamento térmico tem por objetivo reduzir 0 número de microorganismos e inativar enzimas. O processo de conservação térmica mais utilizado é a pasteurização, processo que elimina parte dos microorganismos presentes no produto. Para complementar o processo de conservação, é necessária uma associação com outros sistemas de conservação (refrigeração, conservantes químicos, embalagens herméticas, etc.) para evitar a deterioração do produto pelos microrganismos sobreviventes (VENTURINI, 2005).

Entretanto, a pasteurização favorece a degradação dos compostos que conferem a qualidade sensorial e a nutricional das frutas, fazendo, por isso, necessária a utilização de processos alternativos não-térmicos. A utilização da tecnologia de membranas para clarificação e pasteurização a frio tem permitido a obtenção de produtos com maior valor agregado, graças à preservação de componentes termossensíveis (PALLET et al, 2005).

Segundo Sá et al (2003) e Paula et al (2004), a tecnologia de membranas tem sido avaliada como alternativa para reduzir as perdas sensoriais e nutricionais que podem ocorrer nos processos comumente utilizados para conservação, clarificação e concentração de sucos de frutas. Pallet et al (2005) acrescentam que a concentração de micronutrientes por microfiltração através de membranas é um processo viável e fornece resultados compensadores, em particular em relação a carotenóides e a licopeno.

Em seguida o produto é enviado ao tanque de formulação onde são adicionados os conservantes, antioxidantes e estabilizantes. A adição destas substâncias deve estar de acordo com a legislação vigente e constar do rótulo do produto. Após a formulação final, o produto é envasado sob condições higiênicas em embalagens apropriadas (VENTURINI, 2005). 
Importante destacar que a qualidade dos sucos é influenciada por vários fatores que comprometem suas características químicas (composição), físicas (turbidez, separação de fases sólido/ líquido), organolépticas (aroma, sabor, cor, consistência) e nutricionais (vitaminas). Tais fatores, juntamente com as alterações que ocorrem durante o acondicionamento, distribuição e estocagem irão influenciar a vida-de-prateleira do produto (GRAUMLICH et al., 1986; PRATI et al, 2003).

\subsection{A Indústria de bebidas no contexto da alimentação saudável}

Por meio de uma dieta adequada em quantidade e qualidade o organismo adquire a energia e os nutrientes necessários para o bom desempenho de suas funções e para a manutenção de um bom estado de saúde (MONDINI e MONTEIRO, 1994).

Os danos para a saúde que podem decorrer do consumo insuficiente de alimentos - desnutrição - ou do consumo excessivo - obesidade - são há muito conhecidos. Mais recentemente, entretanto, acumulam-se evidências de que características qualitativas da dieta são igualmente importantes na definição do estado de saúde em particular no que se refere a doenças crônicas da idade adulta (MONTEIRO et al, 2000)

Nos países em desenvolvimento, onde o crescimento econômico ocorre paralelamente a rápidas transformações demográficas e a uma má distribuição de renda, passam a coexistir, nos diferentes estratos populacionais, hábitos alimentares praticados tanto nas nações pobres quanto nas ricas. Esse cenário de transição nutricional tem sido também identificado no Brasil (MONDINI e MONTEIRO,1994). Popkin (2000) acrescenta que, nos últimos anos, tais transformações vêm ocorrendo no Brasil, no que diz respeito ao padrão demográfico e ao perfil de doenças e mortalidade das populações. Ainda, associadas às mudanças econômicas, sociais e demográficas, observam-se 
alterações na estrutura da dieta e, conseqüentemente, diversas repercussões na saúde populacional.

Nas três últimas décadas foi evidenciada substituição crescente de proteínas vegetais por animais e de carboidratos por lipídios nas sete maiores regiões metropolitanas do País, indicando elevação nos riscos potenciais de doenças crônico-degenerativas, que se somam aos problemas carenciais preexistentes (BARRETO, 2001).

Gentil (2006) complementa que o sistema alimentar e a alimentação do brasileiro sofreram mudanças nos últimos 50 anos e essas mudanças se aceleraram com a política internacional de mercado livre, aspecto da globalização, traduzida por Hernandez (2005) como uma homogeneização progressiva e uma perda da diversidade nos planos econômicos, ecológicos e culturais de um país.

Lang e McMichael (1997) comparam essas mudanças com o processo de industrialização da Europa Ocidental e da América do Norte. Há décadas houve um decréscimo da produção e do consumo de alimentos de origem vegetal, incluindo cereais, raízes e tubérculos; um aumento da produção e o consumo de alimentos de origem animal, incluindo as carnes e os laticínios, fontes de proteína animal e de gordura; aliado ao crescimento da produção e do consumo de óleos vegetais e margarina e de açúcar. Em geral, verifica-se o aumento da produção de alimentos com alta densidade energética, processados com gorduras hidrogenadas, açúcar e sal e produtos refinados.

As mudanças das relações familiares, na medida em que a mulher assume uma vida profissional extradomicílio, impossibilitando o compartilhamento das refeições; a perda da identidade cultural no ato das preparações e receitas com a chegada do "evento social" da urbanização e globalização; e o crescente consumo dos alimentos industrializados, pré-preparados ou prontos, que respondem a uma demanda de praticidade, são modificações históricas que contribuem para o processo em discussão, a alteração do hábito de consumo da população (BRASIL, 2005; VENTURINI, 2005).

Neste contexto, a participação da indústria de alimentos é indiscutível. Mello e Novais (1998) citam que a grande mudança relacionada às práticas alimentares 
no que se refere ao consumo de alimentos industrializados e ao hábito de realizar refeições fora do lar ocorreram a partir da segunda metade do século XX. Uma retrospectiva sobre o desenvolvimento da indústria de alimentos no Brasil constatou que, a partir da década de 1970, houve um aumento importante da contribuição dos produtos mais elaborados ou de maior valor agregado para 31,9\% do valor da produção (LIMA, 1979; SATO, 2004).

No início da década de 90, a abertura de mercado possibilitou um crescimento considerável nas importações de alimentos. No período de 1992 a 1995 a importação de produtos alimentares industrializados cresceu em torno de 409\%. O maior aumento foi observado nas preparações alimentícias diversas (1193\%), no cacau e em outras preparações à base de cacau (1237\%) e em preparações à base de cereais (538\%). A importação de laticínios cresceu 970\%, enquanto a de bebidas, a de líquidos alcoólicos e a de vinagre cresceram 640\% (IBGE,1996; DIEZ GARCIA 2003).

Segundo Sartorelli e Franco (2003) no período entre 1988 e 1996, também se identificou um crescimento do consumo de ácidos graxos saturados, açúcares e refrigerantes, em detrimento da redução do consumo de carboidratos complexos, hortaliças, frutas, nas regiões metropolitanas do Brasil. Somado a isso, a crescente substituição dos alimentos in natura, ricos em fibras, vitaminas e minerais, por produtos industrializados tem contribuído para o aumento das doenças crônicas não transmissíveis (BARRETO e CYRILLO, 2001).

Por meio de análise comparativa entre os dados das Pesquisas de Orçamento de Familiar de 1987, 1996 e 2003 é possível se avaliar as tendências de mudanças do padrão alimentar da população brasileira. De modo geral, as mudanças são favoráveis do ponto de vista dos problemas associados à subnutrição (aumento da disponibilidade de calorias per capita e aumento da participação de alimentos de origem animal na alimentação) e desfavoráveis no que se refere à obesidade e às demais doenças crônicas não-transmissíveis aumento da participação na alimentação de gorduras em geral, principalmente de origem animal; de açúcar e diminuição do consumo de cereais, leguminosas, hortaliças e frutas (IBGE, 2004). 
Escrivão et al. (2000) colaboram ao citar que é cada vez mais freqüente o consumo de alimentos industrializados, geralmente de alto conteúdo energético, advindas de gordura saturada, colesterol e açúcar. Em contrapartida, salienta-se a importância do consumo de hortaliças e frutas para o adequado suprimento das necessidades de micronutrientes e de fibras, em razão das atividades fisiológicas desses nutrientes na proteção contra doenças cardíacas, cânceres, diabetes e distúrbios gastrintestinais (BARRETO, 2001).

O aumento do consumo de alimentos industrializados advém, dentre outros fatores, dos avanços tecnológicos que possibilitaram nos últimos anos o aparecimento progressivo de novos produtos, cujo consumo pela população, diminuto, a princípio, cresceu rapidamente devido à intensa e sofisticada propaganda veiculada por meio dos diferentes meios de comunicação, principalmente nos grandes centros urbanos (VENTURINI, 2005).

Notadamente o setor de bebidas foi um dos segmentos que se organizou para atender às novas demandas no setor agroalimentar beneficiando-se com a mudança do perfil da população brasileira e de seus hábitos de consumo (VENTURINI, 2005). Conseqüentemente, houve uma clara mudança de patamar do consumo de alimentos líquidos no país refletindo o lançamento de novos produtos e uma possível melhora das condições econômicas da população (CIPOLLA).

Os sucos de frutas se destacam pelo seu sabor e valor nutricional, entretanto, a elaboração de sucos a partir de frutas in natura tornou-se um inconveniente ao ritmo de vida acelerado da sociedade (LEE e COATES,1999; BERTO, 2003; PINHEIRO, 2006).

Por isso, o consumidor tem demonstrado interesse em consumir produtos "prontos para o consumo", o que impulsionou, a partir da década de 90, o surgimento de diversas marcas comerciais de sucos de frutas industrializados no mercado nacional (LIMA et al, 2000), que conquistaram espaço cada vez maior nas gôndolas de supermercados e nos lares dos brasileiros.

A melhoria do acesso à informação, o grande número de estudos que associa o consumo de alimentos e condições nutricionais à saúde e aos apelos do 
mercado relacionados às bebidas saudáveis e funcionais têm provocado o crescimento da procura por tais produtos. Entretanto, os sucos industrializados ainda têm como forte concorrente os refrigerantes, que apresentam preço final mais baixo, facilitando a massificação do consumo (VENTURINI, 2005).

A tendência apresentada pelo uso de alimentos ricos em açúcares simples é motivo de preocupação tendo em vista os efeitos danosos destes alimentos quando consumidos de forma desarmoniosa em relação ao conjunto da alimentação (CARVALHO et al, 2001). Os refrigerantes constituem a maior fonte de açúcar adicionado na dieta. Segundo Ludwig et al (2001), atualmente metade dos americanos e a maioria dos adolescentes (65\% das meninas e $74 \%$ dos meninos) consomem refrigerantes, diariamente.

Outro fator que contribui para as mudanças nos padrões de consumo é a forte atuação do marketing na indústria alimentícia, com início em meados da década de 70 (YOUNG e NESTLE, 2002). Por serem produtos de demanda primária, os alimentos representam um imenso potencial de mercado consumidor, o que leva os setores de produção, desenvolvimento e industrialização de alimentos a investir cada vez mais em publicidade para despertar efetivamente os motivos para a aquisição de seus produtos (ISHIMOTO e NACIF, 2001).

A escolha cada vez maior pelo consumo de alimentos industrializados levou a um notável crescimento da indústria alimentícia, que tem apresentado como estratégia básica de diferenciação de seus produtos muitos investimentos em técnicas de processamento e marketing, como também em pesquisa para identificação de novas necessidades do consumidor (GONSALVES, 1996).

A veiculação de uma gama de informações relativas aos alimentos é um aspecto que valoriza esse mercado na promoção da saúde coletiva, considerandose que as informações, quando bem conduzidas, se constituem num poderoso instrumento no processo de educação alimentar da população (ISHIMOTO e NACIF, 2001). Alguns autores acreditam que a propaganda deveria ser utilizada como um meio de informação e atualização dos consumidores, orientando-os concreta e lealmente para a realização da opção de compra que thes seja mais adequada e vantajosa. Entretanto, segundo os mesmos, a propaganda na área de 
alimentos explora, em sua maioria, apenas os atributos benéficos, o que pode resultar em um problema de saúde pública (SPERS 1996; CARVALHO e GALLI 1980). Yoshizawa et al (2003) citam que a aquisição de produtos influenciada por estratégias de mercado, acrescida pelas irregularidades encontradas nos rótulos podem causar danos à saúde do consumidor e prejuízos econômicos.

Nesse contexto, Celeste (2001) cita os rótulos dos produtos alimentícios industrializados como um dos fatores que podem influenciar nas escolhas alimentares dos indivíduos, atuando como fonte de informação nutricional aos consumidores; trabalho realizado por Reid e Hendricks (1994) mostrou que 52\% do universo pesquisado se utilizam dessas informações. Os cuidados de rotulagem dos alimentos constituem uma tendência que evidencia o aumento das exigências do consumidor, no sentido da valorização das diversas opções de certificação dos alimentos, buscando assegurar questões relativas, por exemplo, ao processo, à conformidade, à qualidade, à origem e à composição nutricional. (PROENÇA, 2002).Entretanto, há de se destacar que tais dizeres podem ser enganosos, considerando-se o freqüente uso de palavras ambíguas, confusas e termos vagos, uma vez que uma mesma palavra pode expressar significados completamente diferentes de acordo com o fabricante (DIBB, 1997).

De acordo com o item 3, do artigo $6^{\circ}$, da Lei 8078/90 (Código de Proteção e Defesa do Consumidor) é por meio do rótulo dos alimentos que se tem acesso a informações como quantidade, características nutricionais, composição, qualidade e riscos que os produtos poderiam apresentar (BRASIL, 1990). Ainda, o Regulamento Técnico Mercosul Sobre Rotulagem Nutricional de Alimentos Embalados considera que a rotulagem nutricional facilita ao consumidor conhecer as propriedades nutricionais dos alimentos, contribuindo para um consumo adequado dos mesmos e define rotulagem nutricional como "toda descrição destinada a informar ao consumidor sobre as propriedades nutricionais de um alimento". A rotulagem nutricional compreende a declaração de valor energético e de nutrientes e a declaração de propriedades nutricionais, considerada informação nutricional complementar (BRASIL, 2003). 
Yoshizawa et al (2003) comentam sobre a necessidade de que fabricantes de alimentos assegurem aos consumidores o acesso a informações úteis e confiáveis sobre o produto que estão adquirindo. Para conquistar a confiança do cliente, os fabricantes devem atender às exigências legais dos regulamentos técnicos de rotulagem de alimentos. Os mesmos autores realizaram análise em 220 rótulos de produtos alimentícios e concluíram que nenhum dos rótulos analisados encontrava-se totalmente de acordo com os regulamentos técnicos vigentes, sendo que 19,9\% continham informações que poderiam induzir o consumidor a erro. Em contrapartida, estudo realizado pela Universidade Federal do Ceará analisou a rotulagem nutricional de quatro marcas comerciais de suco tropical de maracujá adoçado pronto para beber não encontrou nenhum parâmetro em desacordo com a legislação vigente (FELIPE et al, 2006).

Yoshizawa et al (2003) destacam a necessidade de abordar aspectos de rotulagem de alimentos em programas de educação nutricional a fim de conscientizar o consumidor a respeito das informações que devem ser fornecidas pelo fabricante. Nessa perspectiva, em 2002, Coitinho et al. (2002) compilaram algumas atividades que o Brasil já vinha realizando, citando algumas linhas importantes de atuação como a obrigatoriedade da rotulagem nutricional de produtos alimentícios comercializados; produção de materiais e vídeos para capacitação de professores e profissionais de saúde para realizarem ações educativas junto à população.

Naturalmente, a indústria dará maior destaque às características positivas de seu produto, dessa maneira, é importante analisar mais de uma informação. Por exemplo, um produto, com alto teor de fibra, característica desejável, poderá, em contrapartida, ter alto teor de gordura, de açúcar ou de sódio. Muitas vezes, ainda, os produtos adicionados de vitaminas e minerais, originalmente teriam elevado teor desses micronutrientes, mas as operações de processamento podem diminuir sua bioatividade; em tal situação é comum a indústria recorrer às técnicas de enriquecimento. Neste contexto, é importante analisar se o consumo do produto in natura não é mais saudável e econômico (BRASIL, 2006). 
As técnicas utilizadas para produzir, conservar, transformar os alimentos, em nível doméstico e/ou industrial, podem alterar seu valor nutricional e impactar positiva ou negativamente na saúde do consumidor. Como regra geral, os melhores métodos devem garantir resultado satisfatório com menor alteração das características naturais dos produtos. A maioria dos alimentos e das bebidas consumidas no Brasil tem, pelo menos, um grau mínimo de transformação/processamento (EVANGELISTA, 1994; BRASIL, 2006).

Diante do exposto, é possível se estimar que sucos in natura e processados possam ter diferenças quanto à composição nutricional. Tomando-se como exemplo uma amostra de suco de laranja in natura e uma de suco de laranja industrializado pronto para o consumo sem adição de açúcar, observa-se por meio de uma tabela de composição nutricional (FRANCO, 1992) e das informações apresentadas no rótulo do produto industrializado, observa-se que $200 \mathrm{ml}$ de suco in natura apresentam $57 \%$ a mais de valor energético total, $31 \%$ a mais de carboidratos e $58 \%$ a mais de vitamina $\mathrm{C}$ que o produto processado.

Entretanto, SHILLS et al (2002) comentam que dentre as várias razões benéficas do processamento de alimentos, talvez a mais importante seja a segurança. Embora o processamento possa diminuir o conteúdo nutricional total do alimento, isso significa um pequeno preço a pagar pelo aumento da segurança.

As principais causas de contaminação no processamento podem ocorrer através da superfície externa e o interior do fruto, como também da higienização inadequada de equipamentos e utensílios, tornando-se fontes de contaminação principalmente por bolores e leveduras, favorecendo também a contaminação cruzada, cuja fonte pode ser a matéria-prima, o ar, a poeira e o próprio manipulador (RUSCHEL et al. 2001). Os mesmos autores ao analisarem 52 amostras de sucos de laranja in natura comercializados nas vias públicas de Porto Alegre - RS, determinaram que $5,8 \%$ dessas amostras estavam inadequadas para o consumo quanto ao número de coliformes fecais. SOUZA et al (2006) encontraram elevada contaminação de coliformes totais e fecais, bolores e leveduras em amostras de suco de açaí in natura coletadas em três feiras de 
Manaus, sendo que após a pasteurização houve redução considerável da carga microbiana, aumentando a segurança do produto.

Destaca-se ainda a embalagem como importante fator que contribui para a qualidade final do suco industrializado, uma vez que tem a função de conter o produto de forma a protegê-lo das contaminações externas, quer sejam físicas, químicas ou biológicas, minimizando interações prejudiciais e prolongando a vidade-prateleira desses sucos (FREITAS et al, 2006).

BENDER (1978) menciona uma má compreensão comum de que os alimentos comercialmente processados são sempre nutricionalmente inferiores aos alimentos preparados frescos. Na realidade, a perda dos nutrientes em produtos processados pode ser freqüentemente comparável àquela das preparações de produtos em domicílio. Portanto, algumas perdas acompanharão o processo utilizado para conferir ao produto a segurança e a qualidade, porém, verifica-se ainda que, o aperfeiçoamento dos métodos de processamento torna possível uma maior retenção de nutrientes, preservando ao máximo seu valor nutricional.

\section{Considerações Finais}

A fruticultura é um dos segmentos de maior destaque da economia brasileira e sua atividade tem se destacado no mercado nacional e internacional, colocando o Brasil como um dos três maiores produtores mundiais de frutas. A produção e o consumo de bebidas não-alcoólicas à base de frutas tem apresentado crescimento significativo, ou pela praticidade, segurança, apelo ao tema da alimentação saudável, ou pelo maior acesso da população a produtos considerados supérfluos, devido à estabilização monetária. E a perspectiva é a de que este mercado evolua ainda mais, haja vista que o Brasil apresenta consumo reduzido de tais bebidas quando comparado a países de economia semelhante.

As bebidas embaladas prontas para o consumo oferecem grandes vantagens ao consumidor: garantia da qualidade higiênico-sanitária, maior prazo 
de validade, praticidade tanto para o consumo quanto para o armazenamento e informações nutricionais por meio da rotulagem.

Esta última em especial representa um grande atrativo para o consumidor cada vez mais interessado nos efeitos da alimentação na saúde, seguindo a tendência favorável para o mercado de produtos light, diet ou daqueles considerados saudáveis. Entretanto, deve-se ressalvar a importância da educação nutricional voltada ao consumidor, a fim de que este esteja capacitado a interpretar as informações contidas nos rótulos e a optar pelo melhor produto.

Neste contexto, vale destacar o papel do Estado, ao qual cabe adotar as medidas necessárias para garantir a segurança alimentar de seus cidadãos. Estas medidas englobam, além de ações de educação nutricional para o público em geral, regulamentação específica sobre propaganda e outros recursos publicitários; análise de rótulos, orientação e correção de possíveis distorções antes do lançamento do produto; fiscalização eficiente a nível de mercado varejista, com aplicação de medidas corretivas e punitivas, se necessário.

$\mathrm{O}$ apelo do marketing da indústria quanto à adição de vitaminas e minerais e ainda a venda da imagem do produto como um item que pode e deve ser consumido à vontade por ser considerado "saudável" deve ser analisado com cautela, pois apesar da indiscutível segurança higiênico-sanitária que oferecem, tais produtos podem conter adição de açúcares simples e óbvia redução no teor de fibras quando comparado ao alimento in natura, fatores que podem contribuir para o desenvolvimento de doenças não transmissíveis, como a obesidade.

Destaque ainda para o marketing nutricional voltado para o público infantil, população com elevado grau de vulnerabilidade, que tem apresentado altos índices de obesidade na última década, sendo que o aumento do consumo de produtos industrializados em detrimento ao consumo de alimentos in natura está fortemente relacionado ao aumento destes índices.

A presença de aditivos alimentares nestes produtos, como conservantes, como os compostos à base de sulfito), também deve ser motivo de apreciação no momento da escolha alimentar, haja vista que tais produtos podem estar 
relacionados a alergias ou outros sintomas que possam comprometer a saúde do consumidor.

Diante do exposto, para indivíduos saudáveis, sugere-se consumir tais bebidas industrializadas com moderação, principalmente quando adicionadas de açúcares simples, pois apresentam maior participação de calorias vazias, ou seja, sem nutrientes, no valor calórico total do produto. Importante ressaltar que todo e qualquer alimento deve ser consumido sob a ótica da alimentação saudável, em equilíbrio com outros alimentos, a fim de garantir o suprimento de todas as necessidades nutricionais do indivíduo.

Quanto a indivíduos em condições fisiológicas especiais, principalmente no que se refere à deficiência imunológica, exalta-se a importância de tais produtos industrializados, pois apresentam uma maior garantia da qualidade higiênicosanitária - resultante de um maior controle de qualidade em todo o processo produtivo - predicado ainda mais importante na alimentação destes indivíduos, haja vista a vulnerabilidade de seu sistema de defesa imunológico.

Entretanto, indivíduos portadores de diabetes, ou ainda aqueles que estão como ingestão controlada de nutrientes, devem estar bem atentos às informações apresentadas por tais produtos quando veicularem a informação de que são light ou diet. 


\section{Referências}

ABIR - Associação Brasileira das Indústrias de Refrigerantes e de Bebidas Não Alcoólicas. A Indústria de Refrigerantes e de Bebidas não Alcoólicas, 2005. Disponível on line em: <http://www.abir.org.br>. Consulta em 02 out. 2006.

ABIR - Associação Brasileira das Indústrias de Refrigerantes e de Bebidas Não Alcoólicas. Números Setor Refrigerante, 2002. Disponível on line em: $<$ http://www.abir.org.br> Consulta em 18 de set.2006.

AMORIM, Américo N.G.F.; SANTOS, Fúlvio A. Dos ; MATIAS, P. F. O Crescimento das Tubaínas Ameaça as Marcas Tradicionais? O Panorama do Mercado de Refrigerantes em Recife / PE. In: Simpósio sobre Excelência em Gestão de Tecnologia, 2004, Resende. Anais do Simpósio sobre Excelência em Gestão de Tecnologia. Resende : Associação Educacional Dom Bosco, 2004.

APRIA - Association pour la Promotion Industrie Agriculture. Industrie de jus de fruits. Paris, 1971, Tomo 2. $111 \mathrm{p}$.

AQUINO R.C., PHILIPPI S.T. Consumo infantil de alimentos industrializados e renda familiar na cidade de São Paulo. Revista de Saúde Pública 2002; 36:65560.

BENDER A.E. Food Processing and nutrition. New York: Academic Press, 1978

BERTO, D. Bebidas não alcoólicas - Apelo "saudável" impulsiona consumo. Food Ingredients, n. 24, p. 32-34, 2003. 
BOLETIM NEIT - Núcleo de Economia Industrial e da Tecnologia. Instituto de Economia da Unicamp. Campinas: n 4 , maio 2004.

BORGES, C.P. Curso Teórico - Prático em Engenharia de Bioprocessos. Centro Argentino Brasileiro de Biotecnologia (CABB) - programa de Engenharia Química COPPE/ UFRJ. Rio de Janeiro, 1998.

BRASIL. Ministério da Agricultura. Lei nº 8918 de 14 de julho de 1994.

BRASIL. Ministério da Agricultura. Instrução Normativa $N^{\circ} 1$, de 07 de janeiro de 2000.

BRASIL. Ministério da Agricultura. Instrução Normativa No 12, de 04 de setembro de 2003.

BRASIL. Ministério da Justiça. Secretaria do Direito Econômico. Lei 3078 de 11 de setembro de 1990. Código de Defesa do Consumidor. Disponível em <www.mj.gov.br/dpdc/cdc.htm>. Acesso em 28/01/07.

BRASIL. Ministério da Saúde. Agência Nacional de Vigilância Sanitária. Regulamento Técnico Mercosul sobre Rotulagem Nutricional de Alimentos Embalados. MERCOSUL /GMC /RES N 46, 2003.

BRASIL. Ministério da Saúde. Secretaria de Atenção Básica. Departamento de Atenção Básica. Coordenação Geral da Política de Alimentação e Nutrição. Guia alimentar da população brasileira: promovendo a alimentação saudável. Brasília, 2005. 236 p. (Série A: Norma e Manuais Técnicos).

BRASIL. Presidência da República. Decreto º 2314 de 4 de setembro de 1997. 
BARRETTO, Sérgio Augusto Jábali; CYRILLO, Denise Cavallini. Análise da composição dos gastos com alimentação no Município de São Paulo (Brasil) na década de 1990. Rev. Saúde Pública., São Paulo, v. 35, n. 1, 2001.

CARVALHO CMRG, Nogueira, AMT, Teles JBM, Paz, SMR, Sousa RML. Consumo alimentar de adolescentes matriculados em um colégio particular de Teresina, Piauí, Brasil. Rev Nutr Campinas 2001; 14(2): 85-93

CARVALHO LE, GALLI MLZ. Rotulagem e propaganda na educação alimentar. Alimentação \& Nutrição, 1980; 2:28-37.

CELESTE, Roger K. Análise comparativa da legislação sobre rótulo alimentício do Brasil, Mercosul, Reino Unido e União Européia. Rev. Saúde Pública., São Paulo, v. 35, n. 3, 2001

CIPOLLA, L.E. Neves MF, Amaral TM. Mercado brasileiro de alimentos líquidos nos anos 90 e perspectivas futuras. Disponível on-line: URL: http://www.aduaneiras.com.br).

CLIFF, M. ; DEVER, M.C.; GAYTON, R. Juice extraction process and apple cultivar influences on juice properties. Journal of Food Science. v.56(6):1614-1628, 1991.

COITINHO, D.; MONTEIRO, C. A.; POPKIN, B. M. What Brazil is doing to promote healthy diets and active lifestyles. Public Health Nutr., v. 50, n. 1A, p. 263-267, 2002.

DIBB S. What the label doesn't tell you. London: Thorson; 1997 
DIEZ GARCIA, R.W. Reflexos da globalização na cultura alimentar: considerações sobre as mudanças na alimentação urbana. Rev. Nutr Campinas, v. 16, n. 4, 2003.

Empresas apostam na expansão do segmento de sucos. Panorama do mercado de bebidas. Food Ingredients, n. 24, p. 38, 2003.

EMBRAPA/ SEBRAE. Programa de capacitação tecnológica. Curso de processamento de Frutas, CTAA - Embrapa, Rio de janeiro, 1997, 135p.

ESCRIVÃO, MAMS, OLIVEIRA, FLC, TADDEI, JAAC, LOPEZ, FA - Obesidade exógena na infância e na adolescência - Jornal de Pediatria 76 (supl. 3) - s305s- 309, 2000.

EVANGELISTA, J. Tecnologia de alimentos . 2.ed. São Paulo: Atheneu, 1994. $652 \mathrm{p}$.

FERRARI, C.; SOARES, L. Concentrações de sódio em bebidas carbonatadas nacionais. Ciência e Tecnologia de Alimentos, Campinas, v. 23, n. 3, 2003.

FELIPE E.M.F., COSTA J.M.C, NERES F.P.T.J., OLIVEIRA A.B., SILVA R.A., MAIA G.A. Avaliação da qualidade de suco tropical de maracujá adoçado: caracterização físico-química e rotulagem. Centro de Ciências Agrárias Universidade Federal do Ceará, Fortaleza, CE. Revista Ciência Agronômica, v.37, n.1, p.65-69, 2006

FRANCO, G. Tabela de Composição Química dos Alimentos, $8^{a}$ ed. Rio de Janeiro, Livraria Atheneu, 1992.

FREITAS, C. A. S. et al . Estabilidade do suco tropical de acerola (Malpighia emarginata d.c.) adoçado envasado pelos processos hot-fill e asséptico. Ciênc. Tecnol. Aliment., Campinas, v. 26, n. 3, 2006. 
FRENCH AS, LIN B, GUTHRIE JF. National trends in soft dink consumption among children and adolescents age 6 to 17 years: Prevalence, amounts, and sources, 1977/1978 to 1994/1998. J Am Diet Assoc 2003; 103 (10): 1326-31.

GAVA, A.J. Princípios de Tecnologia de Alimentos. São Paulo, Nobel, 1978.

GENTIL, P.C. Escolhas Alimentares Saudáveis e Não Saudáveis: uma realidade do Distrito Federal. Dissertação (Mestrado em Ciências da Saúde). Faculdade de Ciências da Saúde, Universidade de Brasília, Brasília, 2006.

GONSALVES MIE. Marketing Nutricional. Epistéme, 1996 1(1)239-248.

HERNANDEZ, J. C. Patrimônio e globalização: o caso das culturas alimentares. In: CANESQUI, A. M.; GARCIA, R. W. D. Antropologia e nutrição: um diálogo possível. Rio de Janeiro: FIOCRUZ, 2005. (Coleção Antropologia e Saúde).

IBGE.Instituto Brasileiro de Geografia e Estatística. Anuário Estatístico do Brasil. Brasília; 1996

IBGE. Instituto Brasileiro de Geografia e Estatística .Pesquisa de orçamento famíliar 2002-2003: Primeiros resultados - Brasil e Regiões. 2ªedição, 2004.

ISHIMOTO, E.Y e NACIF M.A.L, Propaganda e marketing na informação nutricional. Brasil Alimentos - n 11 - Dez, 2001.

IBGE - Instituto Brasileiro de Geografia e Estatística. Pesquisa de Orçamentos Familiares (POF) 2002-2003: análise da disponibilidade domiciliar de alimentos e do estado nutricional no Brasil. Rio de Janeiro: IBGE, 2004.

JORGE, Z. L. C.; TREPTOW, R. O. \& ANTUNES, P. L. Avaliação físico-química e sensorial de suco de Maçãs cultivares fuji, granny Smith e seus "blends". Rev. Bras. de Agrociência, v.4, no 1, 15-19, Jan.-Abr., 1998 
LEA, A.G.H., Zumo de manzana, in: In: Ashurst, P.R., Producción y envasado de zumos y bebidas de frutas sin gás, Ed.Acribia, Espana, 1995.p149-189.

LEE, H.S.; COATES, G.A. Vitamin C in frozen, fresh squeezed, unpasteurized, polyethylene-bottled orange juice: a storage study. Food Chemistry, v. 65, p.165168, 1999.

LIMA, V.L.A.G.; MÉLO, E.A.; LIMA, L.S. Avaliação da qualidade de suco de laranja industrializado. Boletim CEPPA, v. 18, n. 1, p. 95-104, 2000.

LOPEZ R. Preferência por hábitos saudáveis gera excelentes oportunidades para o mercado. Engarrafador Moderno, São Paulo, ed.n² 20, 2004.

LUDWIG D.; PETERSON K.;GORTMAKER S. Relation between consumption of sugar-sweetened drinks and childhood obesity: a prospective, observational analysis. Lancet 2001; 357: 505-8.

MELLO, J. M. C.; NOVAIS, F. A. Capitalismo tardio e sociabilidade moderna. In: História da Vida Privada no Brasil. São Paulo: Companhia das Letras, 1998.

MONDINI, Lenise; MONTEIRO, Carlos A.. Mudanças no padrão de alimentação da população urbana brasileira (1962-1988). Rev. Saúde Pública., São Paulo, v. 28, n. 6, 1994.

MONTEIRO, Carlos Augusto; MONDINI, Lenise; COSTA, Renata BL. Mudanças na composição e adequação nutricional da dieta familiar nas áreas metropolitanas do Brasil (1988-1996). Rev. Saúde Pública., São Paulo, v. 34, n. 3, 2000.

MONTEIRO S. Fruta para beber. Frutas e Derivados - Publicação Trimestral do IBRAF. São Paulo: n 1, ed. 1, p.28-31, abril 2006. 
NASCIMENTO, Paulo T. S.; YU, Abraham S. O. Estratégias de negócios e Inovação em mercados de produtos populares. Faculdade de Economia, Administração e Contabilidade. Universidade de São Paulo. Working Paper $n^{\circ}$ 04/010, 2004. Disponível em: <http://www.ead.fea.usp.br/wpapers/2004/04010.pdf>. Consulta em out 06.

NIELSEN S.; POPKIN B.Changes in Beverage Intake Between 1977 and 2001. Am J Prev Med 2004; 27 (3): 205-10.

PAULA B. et al . Melhoria na eficiência da clarificação de suco de maracujá pela combinação dos processos de microfiltração e enzimático. Boletim CEPPA, Curitiba, v. 22, n. 2, jul./dez. 2004.

PALLET D. et al. Aplicação da Tecnologia de Membranas no Processamento de Sucos de Frutas Brasileiras. Cadernos de Ciência \& Tecnologia, Brasília, v. 22, n. 2, p. 427-437, maio/ago. 2005

PEREIRA,B.Processamento agrega valor. Frutas e Derivados - Publicação Trimestral do IBRAF.São Paulo: n 1, ed. 3, p.19-26, set . 2006

PESTRE, L.R.; SILVA, L.F.; MATTA, V.M.; CABRAL, L.M.C. Avaliação da fração retida durante a microfiltração de suco de maracujá. In.:SIMPÓSIO LATINO AMERICANO DE CIÊNCIA DE ALIMENTOS, 5.,2003, Campinas, Resumos... Campinas: UNICAMP, 2003.

PINHEIRO, A.M et al . Avaliação química, físico-química e microbiológica de sucos de frutas integrais: abacaxi, caju e maracujá. Ciência e Tecnologia de Alimentos. Campinas, v. 26, n. 1, 2006.

POPKIN, B. M. The nutrition transition and obesity in the developing world. Journal of Nutrition, 131:871-873, 2001. 
PRATI, P.; MORETTI R.H. ; CARDELLO H.M. Influência da Adição de Ácido Ascórbico na Composição e nas Características Sensoriais da Garapa Parcialmente Clarificada-Estabilizada e Estocada Sob Refrigeração. B.CEPPA, Curitiba, v. 21, n. 2, jul./dez. 2003 Boletim CEPPA, Curitiba, v. 21, n. 2, p. 323342, jul. 2003.

PROENÇA, R.P.C. Desafios Atuais na Alimentação Humana. Departamento de Nutrição, Universidade Federal de Santa Catarina, 2002.Disponível em:

http://www.desenvolvimento.gov.br/arquivo/sti/publicacoes/futAmaDilOportunidade s/rev20011219 07.pdf

QUINTELLA, H.M.; BOGADO, S. Tecnologia de Informação e Competitividade na Indústria de Bebidas Não-Alcoólicas. Relatórios de Pesquisa em Engenharia de Produção da Universidade Federal Fluminense. Rio de janeiro, v.3 , 2003.

REID DJ, HENDRICKS SM. Consumer's understanding and use of fat and cholesterol information on food labels. Can J Public Health 1994;85:334-7

REINOLD, Matthias R. Tendências do mercado mundial de bebidas. Disponível em:http://www.engarrafadormoderno.com.br/arquivo/104dr.pdf>. Consulta em 11 set. 2006.

RODRIGUES, R.B. Aplicação dos processos de Separação por Membranas para Produção de suco Clarificado e Concentrado de Camu camu (Myrciaria dubia).Tese Doutorado em Tecnologia de Alimentos - departamento de tecnologia de Alimentos, Campinas, 146p.2002.

RUSCHEL,C.K.; CARVALHO,H.H.; SOUZA R.B.; TONDO, E.C. - Qualidade Microbiológica e Físico-Química de Sucos de Laranja Comercializados nas Vias Públicas de Porto Alegre/Rs. Ciência e Tecnologia de Alimentos v.21 n.1 Campinas jan./abr. 2001 
SÁ, I. S.; MATTA, V.M.; CABRAL, L.M.C. Concentração de suco de abacaxi através dos processos com membranas. Brazilian Journal of Food Technology, v. 6, p. 53-62, 2003.

SAINZ, R. L.; PERAÇA, R. T.; VENDRUSCOLO, C. T.; GONÇALVES, C. A. D.; VENDRUSCOLO, J. L. Módulo VI: Processamento de polpas e sucos. Pelotas: UFPEL, 2001. 54 p.

SATO, G.S. Desempenho da Indústria Brasileira de Alimentos Pós-Plano Real. Informações Econômicas, SP, v.34, n.1, jan. 2004.

SARTORELLI, Daniela Saes; FRANCO, Laércio Joel. Trends in diabetes mellitus in Brazil: the role of the nutritional transition. Cad. Saúde Pública., Rio de Janeiro, v. 19, 2003

SHILS M.E., OLSON J.A., MOSHE A.S., ROSS C. Processamento de alimentos: Balanço nutricional de segurança e qualidade. In.: Tratado de nutrição moderna na saúde e na doença. São Paulo: Editora Manole, 2002, p.1949-1950.

SOUSA C.; MENDES M. Serviço Brasileiro de Respostas Técnicas - SBRT. Ministério da Ciência e Tecnologia. Jan, 2006.

SOUZA, A.C. Frutas cítricas: singularidades do mercado. Preços Agrícolas, p.810, Mai, 2001.

SOUZA, M. A. C. et al . Suco de açaí (Euterpe oleracea Mart.): avaliação microbiológica, tratamento térmico e vida de prateleira. Acta Amaz., Manaus, v. 36, n. 4, 2006.

SPERS EE. A Segurança dos Alimentos: uma preocupação crescente. Higiene Alimentar, 1996 44(10):18-21. 
TETRA PACK. Empreendedor: inovação, gestão e valor aos negócios. Tetra Pack lança campanha para incentivar consumo de suco pronto e água de coco. Disponível em: <http://www.empreendedor.com.br/ler.php?cod=703>. Acesso em: 07 jan. 2006.

VAILLANT, F.; MILLAN, A.; DORNIER, M.; DECLOUX, M.; REYNES, M.. Strategy for economical optimization of the clarification of pulpy fruit juices using crossflow microfiltration. Journal of Food Engineering, v.48, p.83-90, 2001.

VARNAN, A.H. e SUTHERLAND, J.P., Bebidas: Tecnologia, Química y Microbiologia. Ed.Acribia S.A.., Espana, 487p.1994

VENTURINI F, Waldemar G,Tecnologia de Bebidas: matéria prima, processamento,BPFIAPPCC, legislação e mercado. São Paulo: Edgard Bluncher, 2005.

YOSHIZAWA , N. , POSPISSIL , R.T., VALENTIM A.G., SEIXAS D., ALVES F.S., CASSOU F., YOSHIDA I., SEGA R.A., CÂNDIDO L.M.B.Rotulagem de Alimentos como Veículo de Informação ao Consumidor: Adequações E Irregularidades.

B.CEPPA, Curitiba, v. 21, n. 1, jan./jun. 2003.

YOUNG LR, NESTLE M. The contribution of expanding portion sizes to the US obesity epidemic. Am J Public Health 2002;92:246-9

WILLS, R. H. H.; LEE, T. H.; McGIASSON, W. B.; HALL, E. G.; GRAHAMD. Fisiologia de frutas $y$ hortaliças pos recoleccion, Zaragoza: Acribia, 195p.1984. 